Check for updates

Cite this: RSC Adv., 2017, 7, 44371

Received 10th August 2017

Accepted 10th September 2017

DOI: $10.1039 / \mathrm{c} 7 \mathrm{ra0} 8830 \mathrm{~b}$

rsc.li/rsc-advances

\section{Small organic molecule-mediated hydrothermal synthesis of hierarchical porous hydroxyapatite microspheres by the incorporation of copper ions $\uparrow$}

\author{
Dongqin Xiao, ${ }^{\text {ab }}$ Fei Yang, ${ }^{a}$ Xue Zhou, ${ }^{b}$ Zhu Chen, ${ }^{a}$ Ke Duan, ${ }^{b}$ Jie Weng ${ }^{\star b}$ \\ and Gang Feng*a
}

Hierarchical porous hydroxyapatite $(\mathrm{HA})$ microspheres with a pit in the center were prepared under the synergistic effect of small organic molecules (inositol hexakisphosphate, IP6) and copper ions. A possible mechanism for the formation of the hierarchical porous HA microspheres is proposed.

\section{Introduction}

In recent years, the preparation of hydroxyapatite (HA) particles with specific morphologies has attracted increasing attention in the field of biomedical engineering, because their morphology and structure characteristics have significant influence on the material's properties..$^{1-3} \mathrm{HA}$, as the main inorganic constituent of human bones and teeth, has been widely used as a bone grafting substitute owing to its excellent biocompatibility and bioactivity. The performance of HA particles (e.g. bioactivity, protein-adsorption ability and drug-loading capacity) could be tailored by modifying their size and structure. ${ }^{4,5}$ For instance, sheet-like HA crystals have a much stronger adsorption for bovine serum albumin (BSA) than lysozyme (LSZ) and can be applied to separate BSA from a BSA-LSZ mixed solution. ${ }^{4}$ The introduction of HA whiskers could improve the mechanical properties of HA porous ceramics, ${ }^{6}$ while a mesoporous HA microsphere nanostructure enhances the drug-loading capacity owing to its high specific surface area. ${ }^{5}$ Therefore, controlling HA morphology at the micro/nano-scale has been the focus of intensive research for HA synthesis.

Inspired by biomineralization, organic molecules have been proven to play a key role in inorganic crystals growth. ${ }^{7}$ Inositol hexakisphosphate (IP6, ESI Fig. S1†), a nontoxic polyphosphorylated carbohydrate presented in plant tissues and having six phosphate groups attached to the inositol ring, was successfully used to synthesize hollow HA microspheres under hydrothermal condition in our previous study. ${ }^{8}$ However, the main mineral in human hard tissues is not pure stoichiometric

${ }^{a}$ Research Institute of Tissue Engineering and Stem Cells, Nanchong Central Hospital, The Second Clinical College of North Sichuan Medical College, Nanchong, Sichuan, 637000, China. E-mail: fenggangncch@163.com

${ }^{b}$ School of Materials Science and Engineering, Southwest Jiaotong University, Chengdu, 610031, China. E-mail: jweng@swjtu.cn

† Electronic supplementary information (ESI) available. See DOI: 10.1039/c7ra08830b
HA, but partially substituted by several foreign ions, such as $\mathrm{Na}^{+}, \mathrm{K}^{+}, \mathrm{Sr}^{2+}, \mathrm{Cu}^{2+}, \mathrm{F}^{-}, \mathrm{HPO}_{4}{ }^{2-}$, etc. ${ }^{9}$ These substitutions have different impacts on apatite crystal structure, and further affect the dissolution characteristics of apatite. Researches have shown that carbonate in place of hydroxyl or phosphate of apatite tends to inhibit crystal growth, resulting in crystallinity decrease and solubility increase. ${ }^{10}$ Whereas $\mathrm{F}^{-}$substitution, which has a smaller ionic radius than hydroxyl, tends to shrink the overall unit cell and form highly crystalline apatite. ${ }^{11}$ More importantly, the ions substitutions not only affect the physicalchemical properties of apatite, but also enhance its biological activity. ${ }^{12,13}$ Specifically, as the second essential trace element in human body, copper plays vital roles in angiogenic processes and new tissue formation. ${ }^{14}$ Consequently, $\mathrm{Cu}^{2+}$ was incorporated into bioactive glass scaffolds and found that the scaffolds possessed angiogenesis and osteogenesis as well as antibacterial property. ${ }^{15}$ However, few studies have found the evidence of $\mathrm{Cu}^{2+}$ on the morphogenesis of calcium phosphate crystal. ${ }^{16,17}$

Therefore, to mimic the biological apatite formation process and synthesis of HA crystals with angiogenesis capacity, herein, we used copper ions as additive elements and IP6 as a modifier to control crystal growth and expected to synthesize copperincorporated HA particles with distinct morphology. In this study, we will show that IP6 and copper ions have a synergistic action on the HA morphogenesis under hydrothermal conditions and lead to the formation of hierarchical porous microspheres with pits in the center.

\section{Materials and methods}

In a typical procedure for $\mathrm{HA}$ preparation, $2.85 \mathrm{mmol} \mathrm{Ca}\left(\mathrm{NO}_{3}\right)_{2}$, $0.15 \mathrm{mmol} \mathrm{Cu}\left(\mathrm{NO}_{3}\right)_{2}$ and $100 \mu \mathrm{L}$ IP6 (50 wt\%) were successively dissolved into $30 \mathrm{~mL}$ of deionized water. Subsequently, $\mathrm{Na}_{2} \mathrm{HPO}_{4}$ was dissolved into the above solution and the molar ratio of $(\mathrm{Cu}+\mathrm{Ca}) / \mathrm{P}$ was fixed at 1.67 . The $\mathrm{pH}$ was adjusted to 2.3 by adding $\mathrm{HNO}_{3}$ to obtain transparent solution. Then, urea $\left(2.78 \mathrm{~mol} \mathrm{~L}^{-1}\right.$ ) was added into the transparent solution. 
Subsequently, the liquid was transferred into a Teflon vessel, sealed and heated at $150{ }^{\circ} \mathrm{C}$ for $12 \mathrm{~h}$. The obtained precipitate was collected by centrifugation, rinsed with deionized water and absolute ethanol, and dried at $80{ }^{\circ} \mathrm{C}$ for $72 \mathrm{~h}$. The corresponding products are named as Cu-IP6-HA, while the control samples prepared without the addition of $\mathrm{Cu}^{2+}$ or IP6, are referred to as Pure-HA, IP6-HA and Cu-HA, respectively (see ESI Table $1 \dagger$ ). To investigate the mechanisms of porous hierarchical microsphere formation, intermediate products (Cu-IP6-HA) were collected after reaction for various periods and analyzed.

Microstructures of the products were observed by scanning electron microscopy (SEM, JEOL JSM7001F). Specific surface area and nano-pore size distribution was measured by nitrogen adsorption (MicromeriticsGemini VII2390). The copper ions content was detecting by atomic absorption spectrum (AAS, Hitachi Z-5000). Product phase was characterized by X-ray diffraction (XRD, PANalytical X'PertPro, CuK $\alpha, 45 \mathrm{kV}, 35 \mathrm{~mA}$ ) and Fourier transform infrared spectroscopy (FTIR, Nicolet $5700)$.

\section{Results and discussion}

\subsection{Hierarchical porous microspheres formation}

The control product of Pure-HA was composed of sheets and clusters (Fig. 1a). The mixed constitution is similar to previous studies on the synthesis of calcium phosphate using a high concentration of urea as additive. ${ }^{18}$ When IP6 was added in the solution, a mixture of microspheres (1-25 $\mu \mathrm{m})$ and sheets was obtained (Fig. 1b). In comparison, when only $\mathrm{Cu}^{2+}$ was added, uniformly morphology consisting of flake aggregates (with diameter of $\sim 10 \mu \mathrm{m}$ ) appeared and sticked together (Fig. 1c). However, when IP6 and $\mathrm{Cu}^{2+}$ were both added, the product morphology was significantly changed. Hierarchical porous microspheres (mean diameter: $\sim 20 \mu \mathrm{m}$ ) were constructed by regular assembly of nano-flakes and a pit (diameter: $\sim 5 \mu \mathrm{m}$ )
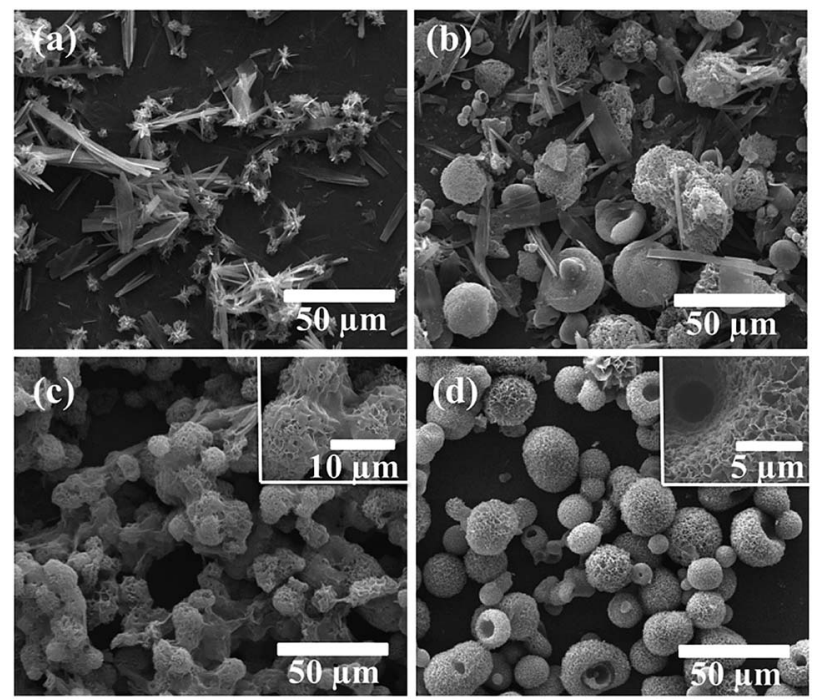

Fig. 1 SEM micrographs showing morphology of (a) Pure-HA, (b) IP6$\mathrm{HA}$, (c) $\mathrm{Cu}-\mathrm{HA}$ and (d) $\mathrm{Cu}-\mathrm{IP} 6-\mathrm{HA}$, respectively. emerged in the center of the microspheres (Fig. 1d). EDS analyses of the nano-flakes showed peaks for $\mathrm{Ca}, \mathrm{P}, \mathrm{O}$ and $\mathrm{Cu}$, with a molar $\mathrm{Ca} / \mathrm{P}$ ratio of 1.46 , suggesting a Ca-deficient apatite phase. The copper ions content of the microspheres quantified by AAS showed a molar $\mathrm{Cu} / \mathrm{Ca}$ ratio of $1.3 \%$, which is much lower than the expected molar $\mathrm{Cu} / \mathrm{Ca}$ ratio of $5 \%$ in the stock solution. The specific surface area of the porous microspheres was $109 \mathrm{~m}^{2} \mathrm{~g}^{-1}$ and pore size distribution showed the existence of mesopores (2-50 nm) and macropores (>50 nm) (ESI Fig. S2 $\dagger$ ). Moreover, H3 type hysteresis loop was observed, indicating of narrow slit-shaped pores formed by plate-like particles.

The crystal phases of all products determined by XRD were shown in Fig. 2a. The four spectra all matched the standard pattern of HA (JCPDS no. 09-0432), suggesting the formation of single phase HA. More specifically, when no IP6 was added, the products of Pure-HA and Cu-HA gave a lower (002)/(300) diffraction intensity ratio compared with those synthesized in the presence of IP6 (IP6-HA and Cu-IP6-HA). These phenomena are related to the morphology of the products. For products of Pure-HA and Cu-HA, which both consisted of sheets and flakes, during the preparation of XRD samples, they tended to lie flat with a plane facing up, thus giving a strong (300) diffraction and weak (002) diffraction. However, with IP6 molecules addition, the $(002) /(300)$ intensity ratio increased, in accordance with their spherical-like shape. These results suggested IP6 and $\mathrm{Cu}^{2+}$ had little impact on HA phase purity but had an effect on the shape of HA crystals.

In addition, the FTIR spectra of all products (Fig. 2b) also exhibited the characteristics bands of HA. The stretching vibration absorption peaks at 960, 1033 and $1111 \mathrm{~cm}^{-1}$,
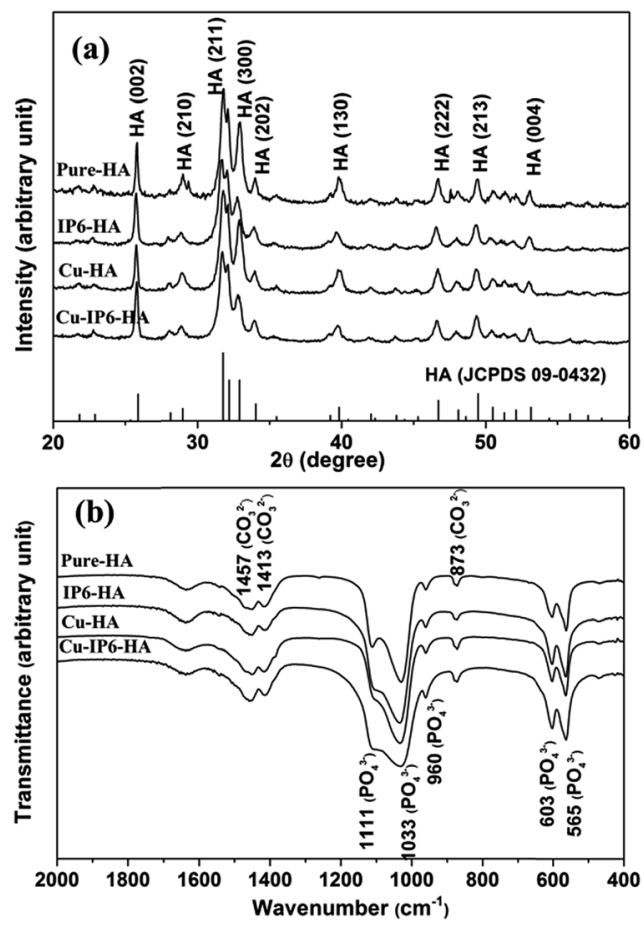

Fig. 2 (a) XRD patterns and (b) FTIR spectra of different products. 
bending vibration peaks at 565 and $603 \mathrm{~cm}^{-1}$ were the characteristic bands of $\mathrm{PO}_{4}{ }^{3-} \cdot{ }^{19}$ The peak at $873 \mathrm{~cm}^{-1}$ were attributed to $v_{2}$ vibrations of $\mathrm{CO}_{3}{ }^{2-}$, the bimodal peaks at 1413 and $1457 \mathrm{~cm}^{-1}\left(v_{3}\right)$ were corresponding to $\mathrm{CO}_{3}{ }^{2-}$ substituting $\mathrm{PO}_{4}{ }^{3-}$ (B-type substitution). ${ }^{20}$ This phenomenon indicated that all products were carbonated apatites.

\subsection{Formation process of hierarchical porous microspheres}

To investigate the formation process of hierarchical porous HA microspheres, intermediate products were collected and analyzed by SEM (Fig. 3). At $10 \mathrm{~min}$, smooth spherical particles with diameter ranging from $\sim 200 \mathrm{~nm}$ to $\sim 2 \mu \mathrm{m}$ appeared. At $15 \mathrm{~min}$, the spherical particles enlarged to $\sim 3 \mu \mathrm{m}$ and the sphere surface turned rough. At $30 \mathrm{~min}$, the spheres further
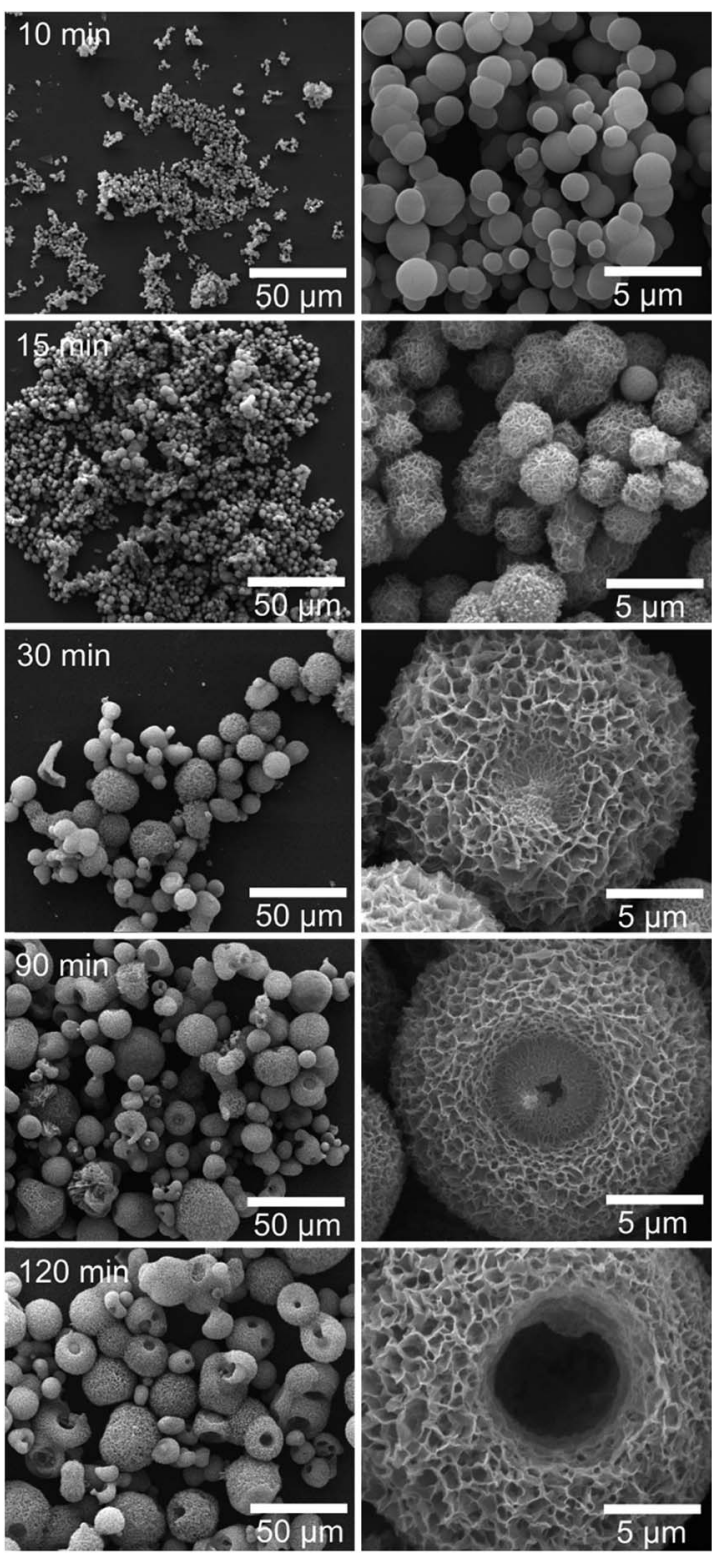

Fig. 3 SEM micrographs of products formed after reaction for various periods (left column: low magnification, right column: high magnification). enlarged to $\sim 15 \mu \mathrm{m}$ and showed porous structures constructed by regular assembly of nano-flakes (thickness: $\sim 20 \mathrm{~nm}$ ). At 90 min, a concave part with diameter of $\sim 5 \mu \mathrm{m}$ was formed in the center of the porous microspheres. With time further increase to $120 \mathrm{~min}$, the central concave turned into a hollow pit. Meanwhile, the intermediate products were also characterized by XRD and FTIR (Fig. 4). XRD indicated a transition from an amorphous phase to HA crystals. FTIR revealed that the relative intensities of peaks attributed to $\mathrm{C}-\mathrm{O}-\mathrm{P}$ stretching (853 and $993 \mathrm{~cm}^{-1}$ ) and peaks attributed to $\mathrm{PO}_{4}{ }^{2-}$ (539 and $1134 \mathrm{~cm}^{-1}$ ), featuring the characteristic peaks of calcium/ copper salt of IP6 (Ca/Cu-IP6), ${ }^{21}$ decreased with the reaction time. While the relative intensities of peaks attributed to $\mathrm{PO}_{4}{ }^{3-}$ bending (563 and $603 \mathrm{~cm}^{-1}$ ) and stretching (1032 and $\left.1111 \mathrm{~cm}^{-1}\right),{ }^{19}$ matching the characteristic peaks of HA, increased with time. Based on the analysis above, the hierarchical porous HA microspheres were formed probably via an amorphous nanosphere-directed HA crystal growth.

Based on the analysis above, the schematic growth process of the hierarchical porous HA microspheres was suggested as follows. With the heating temperature increase, urea gradually decomposed and the solution became increasingly alkaline. Consequently, the initial nuclei were formed and amorphous nanospheres appeared. In our previous study, IP6-assisted formation of amorphous solid microspheres was proposed. ${ }^{\mathbf{8}}$ On one hand, IP6 with highly negatively charge chelated $\mathrm{Ca}^{2+}$ or $\mathrm{Cu}^{2+}$ and the chelation formed metallic-IP6 amorphous nanospheres. On the other hand, amorphous calcium/copper phosphate nuclei first formed according to Eanes' report, ${ }^{22}$ but
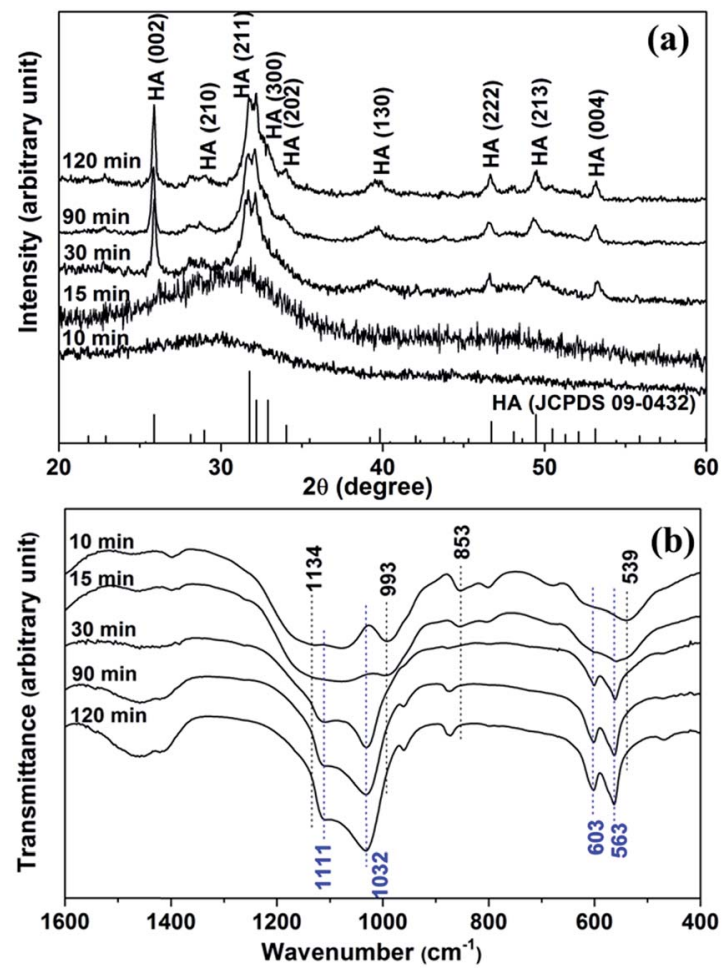

Fig. 4 (a) XRD patterns and (b) FTIR spectra of products formed after reaction for various periods. 
prevented to grow rapidly due to IP6 entanglement, similar to the amorphous $\mathrm{CaCO}_{3}$ particles stabilized by IP6. ${ }^{23}$ Therefore, the amorphous nanospheres most likely consisted of the metallic-IP6 spheres and metallic-phosphate spheres. Furthermore, with the dissociation of metallic-IP6 complexes and the dissolution of the amorphous metallic-phosphate under hydrothermal condition, the nucleation and growth of HA crystals became realistic. Thus, HA nano-flakes formed and assembled into microspheres under the synergistic effect of IP6 and $\mathrm{Cu}^{2+}$. Our previous report indicated that IP6 played a key role in the formation of HA microspheres with nano-structure surface. $^{8}$ When the IP6 concentration was greater than or equal to $1.7 \mathrm{v} / \mathrm{v} \%$, uniform-morphological microspheres formed, while the IP6 concentration was less than or equal to $1 \mathrm{v} / \mathrm{v} \%$ IP6, a mixture of whiskers and spheres both generated. Similarly, in this article, spheres and sheets appeared at $0.33 \mathrm{v} / \mathrm{v} \%$ IP6. However, the mixture turned to uniformly hierarchical porous HA microspheres after $\mathrm{Cu}^{2+}$ was added, suggesting the synergistic effects between IP6 and $\mathrm{Cu}^{2+}$ on HA morphogenesis. Zhang et al. found that the calcite crystal morphology change was caused by $\mathrm{Mg}^{2+}$ being non-uniformly incorporated into the crystal surface. ${ }^{24}$ Therefore, we speculated that $\mathrm{Cu}^{2+}$ might be incorporated into the calcium phosphate crystal surface and further lead variation in HA morphology.

In addition, it was noteworthy that the central pit of the microspheres was likely associated with urea decomposition. The products of Cu-IP6-HA (ESI Fig. S3†) prepared with different urea concentration revealed that pits formed in the center of the microspheres at $1.39 \mathrm{~mol} \mathrm{~L}^{-1}$ urea, but no pits formed at $0.56 \mathrm{~mol} \mathrm{~L}^{-1}$ urea. The difference morphologies indicated that urea concentration had impacts on the pit appearance and microspheres formation. Consequently, it was concluded that high concentration of urea was not only as the precipitation agent to control the crystal growth and morphology, but as a corrosive to erode the microsphere. This "base-erosion" mechanism was proposed by Chen et al. ${ }^{25}$ who proposed that the erosion occurred from the microsphere center point to the outside gradually. In this experiment, a similar phenomenon was observed during the pit formation (Fig. 3). From the effects of urea concentration on calcium phosphate growth, it was concluded that the appropriate amount of urea was the critical factors for pits formation. Although the more detailed formation mechanism needs to be further explored, the hierarchical porous HA microspheres prepared by this methods owing high specific surface and copper ions have potential applications in the drug loading and as a multifunctional bioactive materials to promote angiogenesis and osteogenesis.

\section{Conclusions}

In this study, hierarchical porous microspheres with pits in the center were prepared by copper-incorporation and introducing IP6 as a morphology modifier. The presence of IP6 and copper ions showed a synergistic effect on microspheres formation. The formation mechanism was suggested to be an amorphous nanosphere-directed crystallization process. Also, the urea concentration played a key role in the pits evolution. Therefore, this process provides a simple and novel route for the synthesis of copper-incorporated porous HA microspheres for potential applications such as drug delivery and stimulating vascularization for bone tissue repair.

\section{Conflicts of interest}

There are no conflicts to declare.

\section{Acknowledgements}

This study was supported by the National Basic Research Program of China (973 Program, 2012CB933600), the National Natural Science Foundation of China (51572228), the Applied Fundamental Program of Science and Technology Department of Sichuan Province (2016JY0123) and the Key Project of Education Department of Sichuan Province (17ZA0178).

\section{References}

1 S. D. Jiang, Q. Z. Yao, G. T. Zhou and S. Q. Fu, J. Phys. Chem. $C$, 2012, 116, 4484-4492.

2 D. Xiao, X. Zhou, H. Li, Y. Fu, K. Duan, X. Lu, X. Zheng and J. Weng, J. Eur. Ceram. Soc., 2015, 35, 1971-1978.

3 C. Qi, Y. Zhu, C. Wu, T. Sun, Y. Jiang, Y. Zhang, J. Wu and F. Chen, RSC Adv., 2016, 6, 9686-9692.

4 K. Kandori, H. Hamazaki, M. Matsuzawa and S. Togashi, Adv. Powder Technol., 2014, 25, 354-359.

5 Y. P. Guo, T. Long, S. Tang, Y. J. Guo and Z. A. Zhu, J. Mater. Chem. B, 2014, 2, 2899-2909.

6 Z. Fang, Q. Feng and R. Tan, Ceram. Int., 2013, 39, 88478852.

7 A. Arakaki, K. Shimizu, M. Oda, T. Sakamoto, T. Nishimura and T. Kato, Org. Biomol. Chem., 2014, 13, 974-989.

8 D. Xiao, Z. Tan, Y. Fu, K. Duan, X. Zheng, X. Lu and J. Weng, Ceram. Int., 2014, 40, 10183-10188.

9 S. C. Cox, P. Jamshidi, L. M. Grover and K. K. Mallick, Mater. Sci. Eng., C, 2014, 35, 106-114.

10 L. Wang and G. H. Nancollas, Chem. Rev., 2008, 108, 46284669.

11 E. Moreno, M. Kresak and R. Zahradnik, Caries Res., 1977, 11, 142-171.

12 Y. Qiao, W. Zhang, P. Tian, F. Meng, H. Zhu, X. Jiang, X. Liu and P. K. Chu, Biomaterials, 2014, 35, 6882-6897.

13 S. Yoshizawa, A. Brown, A. Barchowsky and C. Sfeir, Acta Biomater., 2014, 10, 2834-2842.

14 N. J. Lakhkar, I. H. Lee, H. W. Kim, V. Salih, I. B. Wall and J. C. Knowles, Adv. Drug Delivery Rev., 2013, 65, 405-420.

15 C. Wu, Y. Zhou, M. Xu, P. Han, L. Chen, J. Chang and Y. Xiao, Biomaterials, 2013, 34, 422-433.

16 V. Stanić, S. Dimitrijević, J. Antić-Stanković, M. Mitrić, B. Jokić, I. B. Plećaš and S. Raičević, Appl. Surf. Sci., 2010, 256, 6083-6089.

17 M. Schamel, A. Bernhardt, M. Quade, C. Würkner, U. Gbureck, C. Moseke, M. Gelinsky and A. Lode, Mater. Sci. Eng., C, 2017, 73, 99-110. 
18 Z. Mohammadi, A. S. M. Mesgar and F. Rasouli-Disfani, Ceram. Int., 2016, 42, 6955-6961.

19 S. Koutsopoulos, J. Biomed. Mater. Res., 2002, 62, 600-612.

20 B. Jokić, M. Mitrić, V. Radmilović, S. Drmanić, R. Petrović and D. Janaćković, Ceram. Int., 2011, 37, 167-173.

21 K. Ganesan and M. Epple, New J. Chem., 2008, 32, 1326-1330.
22 J. L. Meyer and E. D. Eanes, Calcif. Tissue Int., 1978, 25, 5968.

23 A. W. Xu, Q. Yu, W. F. Dong, M. Antonietti and H. Colfen, Adv. Mater., 2005, 17, 2217-2221.

24 Y. Zhang and R. A. Dawe, Chem. Geol., 2000, 163, 129-138. 25 Z. Chen and L. Gao, Cryst. Growth Des., 2008, 8, 460-464. 